\title{
The Challenging Place of Natural Hazards in Disaster Risk Reduction Conceptual Models: Insights from Central Africa and the European Alps
}

\author{
Caroline Michellier ${ }^{1} \cdot$ Patrick Pigeon $^{2} \cdot$ André Paillet $^{2} \cdot$ Théodore Trefon $^{3} \cdot$ \\ Olivier Dewitte $^{1} \cdot$ François Kervyn $^{1}$
}

Published online: 28 April 2020

(C) The Author(s) 2020

\begin{abstract}
Based on a literature review and two case studies, this article presents the difficulties inherent in the main disaster risk reduction conceptual models. The method used to highlight such evidence is to compare two programs on disaster risk reduction with mainstream conceptual models. The authors participated in these programs, which were confronted with the need to integrate contributions and insights from both earth and social sciences. Our analysis found that the existing main conceptual models were unable to do justice to disaster risk reduction needs. This finding encouraged us to critique these models. Further effort led us to present possible solutions to compensate for the shortcomings of current models while taking into account the contextualization and dynamics of phenomena, as well as grappling with the more explicit integration of hazards and hazard risk into model design.
\end{abstract}

Keywords Central Africa - Conceptual models · Disaster risk reduction - Natural hazards $\cdot$ Northern French Alps

Caroline Michellier

caroline.michellier@africamuseum.be

1 Natural Hazards Service, Royal Museum for Central Africa, 3080 Tervuren, Belgium

2 EDYTEM Laboratory, Université de Savoie-Mont-Blanc, 73376 Le Bourget du lac, France

3 Geodynamics and Mineral Resources Service, Royal Museum for Central Africa, 3080 Tervuren, Belgium

\section{Introduction}

In disaster risk reduction (DRR) research, conceptual models are defined as graphical representations of the relationships between disaster risk components (Birkmann 2006; Cutter et al. 2008). Disaster risk reduction conceptual models should refer to seminal works such as those of Hewitt (1983), Blaikie et al. (1994), and Lewis (1999). Since the appearance of these groundbreaking scholarly works, the number of contributions has increased steadily in the first 2 decades of the Twenty-first Century. ${ }^{1}$ This increase explains why presenting a comprehensive review of existing models is inconclusive (as with Nojavan et al. 2018). If different DRR conceptual models (for example, those employed by Turner et al. 2003; Wisner et al. 2004; Birkmann and Wisner 2006), or those that reflect socialecological systems thinking (Renaud et al. 2013; Rockström et al. 2014) or others that do not (Shi and Kasperson 2014), are presented in the scientific literature as responses that could be adapted to various contexts, they are unconvincing. The recent rise of resilience in literature on DRR exacerbates the challenge of representing how disasters are prevented by conceptual models. This is notably the case with respect to disaster risk dynamics (Gunderson and Holling 2002; Cumming 2011; Pigeon and Rebotier 2016; Fra Paleo 2019). This point also depends on the various solutions that merit evaluation as to how resilience could be defined. Because resolution of this conundrum

\footnotetext{
${ }^{1}$ Gunderson and Holling (2002), Turner et al. (2003), Garcia-Acosta (2005), Cumming (2011), Menoni and Margottini (2011), Baccini and Brunner (2012), Renaud et al. (2013), Rockström et al. (2014), Shi and Kasperson (2014), Aitsi-Selmi et al. (2016), Fekete and Hufschmidt (2016), Pigeon and Rebotier (2016), Gill and Malamud (2017), Collins (2018) and Kelman (2018).
} 
would demand a specific review and a separate, dedicated article, the issue will not be addressed here.

This article highlights gaps that still exist between conceptual models and their relevance to policy research frameworks-as well as to gaps with observations from case studies. The shortcoming related to the place given to hazards in major conceptual models, as is the case with the Pressure and Release (PAR) model and its iterations (Wisner et al. 2004), or with the "disaster system" model (Shi and Kasperson 2014), reinforces the need to rethink the relevance of dominant conceptual approaches. The same shortcoming also identifies discrepancies between conceptual models and the basic structures of international programs that deal with disaster risk reduction and fieldwork observations. Our approach addresses discrepancies between two dominant conceptual models and the structure of two international programs. Our conclusion is an invitation to reconsider the place devoted to "natural hazards" in conceptual models, while putting forward solutions to improve existing models.

This article is based on a program carried out in eastern Democratic Republic of Congo (DRC), and another one located in the European Alps, at the border between Switzerland and France. They are admittedly examples of international programs that focus on areas with quite different physical and human characteristics with, nevertheless, the commonality of inadequate conceptual models to deal with DRR.

GeoRisCA (Georisk in Central Africa) ${ }^{2}$ is a project of BELSPO (Belgian Federal Science Policy Office) ${ }^{3}$ and pursues sustainable development research and DRR efforts aimed at analyzing earthquake, volcanic, and landslide hazards, along with population vulnerability to those hazards. The project's aim was to support risk management in the area stretching from North Kivu in the DRC to northern Burundi and western Rwanda (Michellier et al. 2018). The analysis was derived from studies at both regional and local scales, focusing on two specific urban sites: Bukavu (South Kivu Province) and Goma (North Kivu Province). A key objective was to develop decision-making tools for local institutions in charge of DRR.

The SF INTERREG ${ }^{4}$ (Swiss-French interregional cooperation programme) contributed to preventing disasters relating to floods on the upper Rhône River watershed

\footnotetext{
$2 \mathrm{http://georisca.africamuseum.be.}$

3 https://www.belspo.be/.

4 "European Territorial Cooperation (ETC), better known as Interreg, is one of the two goals of cohesion policy and provides a framework for the implementation of joint actions and policy exchanges between national, regional and local actors from different Member States." https://ec.europa.eu/regional_policy/en/policy/cooperation/europeanterritorial/ ETC funds programs on joint actions between European countries, as is the case here between Switzerland and France.
}

(Dupont and Pigeon 2008; Lopez-Pelaez and Pigeon 2011). SF INTERREG dealt with two closely related priorities for decision makers, territorial administrators, and scientists: water and flood risk managements. These actors, however, do not necessarily work together, despite obvious links between their fields of interest. The structure of SF INTERREG's final report, ${ }^{5}$ moreover, reflects an absence of synergy. The first part assesses the situation of water as both resource for and threat to people living in the upper catchment of the Rhône. The second part addresses the problems the integrative assessment identified. The third part proposes solutions to prevent further flood disasters and failures in water provision, emphasizing how both issues are interconnected.

Despite the geographical and policy differences between GeoRisCA and SF INTERREG, their comparison highlights similarities because they both address closely interlinked fundamental issues. These stem from the difficulties in finding a conceptual model on disaster risk reduction that integrates the diverse contributions from natural sciences, on the one hand, and those of social sciences, on the other. This integration should be a prerequisite from a conceptual perspective, however, especially considering humankind's capacity to transform the earth and its environment, which has led to the development in the beginning of the twenty-first century of the concept of the Anthropocene (Magny 2019). This trend reveals the importance of reconsidering the existing divide between natural and social sciences. It likewise challenges the place given to so-called natural hazards in existing models. Indeed, both programs and international research on DRR acknowledge the limited relevance of models to improve disaster risk management. In response to these shortcomings, both programs had to design their own solutions on how to integrate the various contributions to DRR understanding and management. Yet, the solutions found remain unsatisfactory.

The reasons why a basic conceptual model that outlines a coherent and comprehensive research framework is difficult to design are discussed in Sect. 2. What is the place of natural hazards in existing conceptual models? How can relationships between basic components of disaster risk definition and their evolution be represented? We suggest that answering these questions could lead to a better integration of contributions from geosciences with those from social sciences. The ultimate benefit would be greater coherence in disaster prevention programs.

This article also addresses this challenge by going back to the basic definitions of risk currently used in the literature on DRR. It continues by detailing three major

\footnotetext{
$\overline{5 \text { https://www.risknet-alcotra.org/fr/index.cfm/base-donnees-projets/ }}$ haut-rhone.html.
} 
conceptual models whose shortcomings explain why we argue for a more comprehensive, consistent, and contextsensitive option. Lastly, the article suggests solutions for a conceptual model that integrates more effectively contributions from earth and social sciences for future DRR research.

\section{Definitions of Disaster Risk: Evolving and Still Unsatisfactory}

The glossary of the Global Assessment Report 2015 (UNISDR 2015, p. 268) offers the following definition: "disaster risk is considered to be a function of hazard, exposure and vulnerability." UNISDR refers to books such as Wisner et al. (2004), and examples of the dominant literature appear in the references of UNISDR's 2015 assessment report to which more than one hundred reviewers contributed. Since then, UNISDR decided to reconsider how disaster risk should be defined. The current official definition is: "The potential loss of life, injury, or destroyed or damaged assets which could occur to a system, society or a community in a specific period of time, determined probabilistically as a function of hazard, exposure, vulnerability and capacity" (UNISDR 2017, p. 98). In contrast to the emerging agreement on the definition of disaster risk, it is still not possible to find consensus on how disaster is defined.

Disaster is usually defined in accordance with damage intensity levels. According to the Centre for Research on the Epidemiology of Disasters (CRED 2015), a disaster corresponds to any event exceeding 10 fatalities and/or 100 affected individuals. This definition is highly challenged because it differs depending on the disaster inventory database used (Lopez-Pelaez and Pigeon 2011; Menoni and Margottini 2011; UNISDR 2015). Shi and Kasperson (2014, p. 3) consider that "disaster losses and damages are consequences of the interactions of hazards $(\mathrm{H})$, exposures (S) and the environment system (E) in which disasters occur," and they do not give any quantitative threshold for the definition of a disaster based on the intensities of damages experienced during an event. Their definition, moreover, does not integrate the relevant concept of vulnerability.

Strikingly, one component of the definition of disaster risk, which is presented last, if at all, is that of disaster risk reduction policies. Sometimes they are integrated in the definition by reference to capacities, as in the UNISDR glossary (2017, p. 98), where capacity refers to "infrastructure, institutions, human knowledge and skills and collective attributes such as social relationships, leadership and management." But most definitions do not explicitly take into account disaster risk reduction policies. This is problematic because it implies that disaster reduction does not need to address policy issues and does not take into account how policies are designed and implemented ( $\mathrm{Pi}$ geon and Rebotier 2016).

Hazard is referred to as "a dangerous phenomenon, human activity or condition that may cause loss of life, injury or other health impacts, property damage, loss of livelihoods and services, social and economic disruption, or environmental damage" (UNISDR 2009, p. 17). Nevertheless, the recognition of human capacity to transform hazards, whether intentionally or unintentionally, has increased, as noted by Kelman (2018). This shift should challenge the usual emphasis on hazards in the basic definitions of disaster risk. Challenging the first place still usually given to hazards is consistent with the understanding of risk as resulting mainly from the structures and evolutions of human societies (Hewitt 1983; Blaikie et al. 1994; Garcia-Acosta 2005).

The second main component arising in the basic definitions of risk, vulnerability, may be defined as "an intrinsic predisposition to be affected or to be susceptible to damage" (Birkmann 2006, p. 12) even though "the different definitions or approaches show it is not clear just what 'vulnerability' stands for [as] a scientific concept" (Birkmann 2006, p. 11). On the contrary, the definition of vulnerability given by Shi and Kasperson (2014, p. 311) seems clearer: "vulnerability is the severity of disasters caused by hazards. It is interpreted by a curve or function reflecting disaster loss [...]." But such an understanding of disasters-mainly driven by hazards (because vulnerability is considered to be passive)-is under increased scrutiny (Wisner et al. 2004; Garcia-Acosta 2005). Oliver-Smith (1986), Hewitt (1983), and Lewis (1999) have stressed that vulnerability refers to a social process that provides the root causes of a disaster (Blaikie et al. 1994). According to Lewis (2011, p. 471): "Vulnerability is dynamic, not static." This view is consistent with the broad definition of vulnerability provided by UNISDR (2017, p. 100): "the conditions determined by physical, social, economic and environmental factors or processes which increase the susceptibility of an individual, a community, assets or systems to the impacts of hazards." Based on the work of Birkmann (2006) and Fekete and Hufschmidt (2016), it is clear that vulnerability is an extremely controversial and heterogeneous concept; more than 30 different definitions can be found.

This helps explain why exposure is sometimes added to the basic definition of risk. Exposure depicts the assets (structures, populations, and economy) likely to be affected by a hazard, while "vulnerability has a physical, social, economic, and environmental dimension" (Birkmann 2006, p. 23). According to Shi and Kasperson (2014, p. 3), "exposures mainly include social and economic elements." 
The UNISDR (2017, p. 99) definition of exposure looks very similar to the position Birkmann (2006) defended: "The situation of people, infrastructure, housing, production capacities and other tangible human assets located in hazard-prone areas."

The distinction between exposure and vulnerability is considered relevant by UNISDR (2017), mainly because exposure is more likely to be quantified (Guillier 2017) while "social vulnerability is poorly understood and difficult to measure" (Aitsi-Selmi et al. 2016, p. 10). Yet, when it comes to understanding why a disaster occurs, this distinction between vulnerability and exposure could be considered less crucial, as argued by Kelman (2018, p. 285): "interactions amongst conditions, characteristics, and circumstances are as important to disaster-related outcomes as the conditions, characteristics, and circumstances themselves, blending and deepening the ideas behind the definitions of 'vulnerability' and 'exposure."' As illustrated by the two buildings in the Arve River floodprone area (Figs. 1, 2), it makes sense to separate these concepts. Indeed, both buildings on Fig. 2 are exposed to floods because they were built on the river floodplain, as shown by the last flood experience dating back to 1968 (Dupont and Pigeon 2008). Nowadays, both buildings belong to the risk prevention plan blue zone of the area (Fig. 1).

In France, a risk prevention plan officially maps which areas are flood-prone, according to their degree of exposure. Following the enforcement of a risk prevention plan, it is not possible to build on red zones-a way of reducing exposure to floods. Besides, the objective of delineated risk prevention plan blue zones is to try reducing vulnerability. On blue zones, it is possible to build, but landowners are supposed to take some risk reduction measures to protect themselves. In our example, one of the landowners (building 2) did so, but the other one (building 1) did not take those recommendations into consideration. Also mapped on Fig. 1, dikes help reducing risk level: these works contribute to set flood risk level at medium and reinforce the feeling of safety.

Therefore, building 1 is presumed more vulnerable to floods compared to building 2 because this latter integrates flood risk by being raised on backfills that reduce expected damage in case of flood. The difference between both exposed buildings, yet not equally vulnerable, would also consider the need to take DRR policies into consideration, as well as examine how the policies were implemented. While vulnerability cannot be reduced to adaptations of buildings, and the example provided addresses only part of the issue, it does illustrate the difference between exposure and vulnerability, and therefore the relevance of considering them as separate elements.

This discussion of definitions is important because as a consequence of these divergences, various questions inevitably arise when trying to integrate the main risk components into conceptual DRR models.

\section{The Choice of Conceptual Models in the Literature on Disaster Risk Reduction}

The main conceptual models in DRR found in the relevant scientific literature are frequently quoted in reports published by international institutions dedicated to disaster prevention (Duncan et al. 2014). We have consequently chosen to discuss three models based on previous syntheses

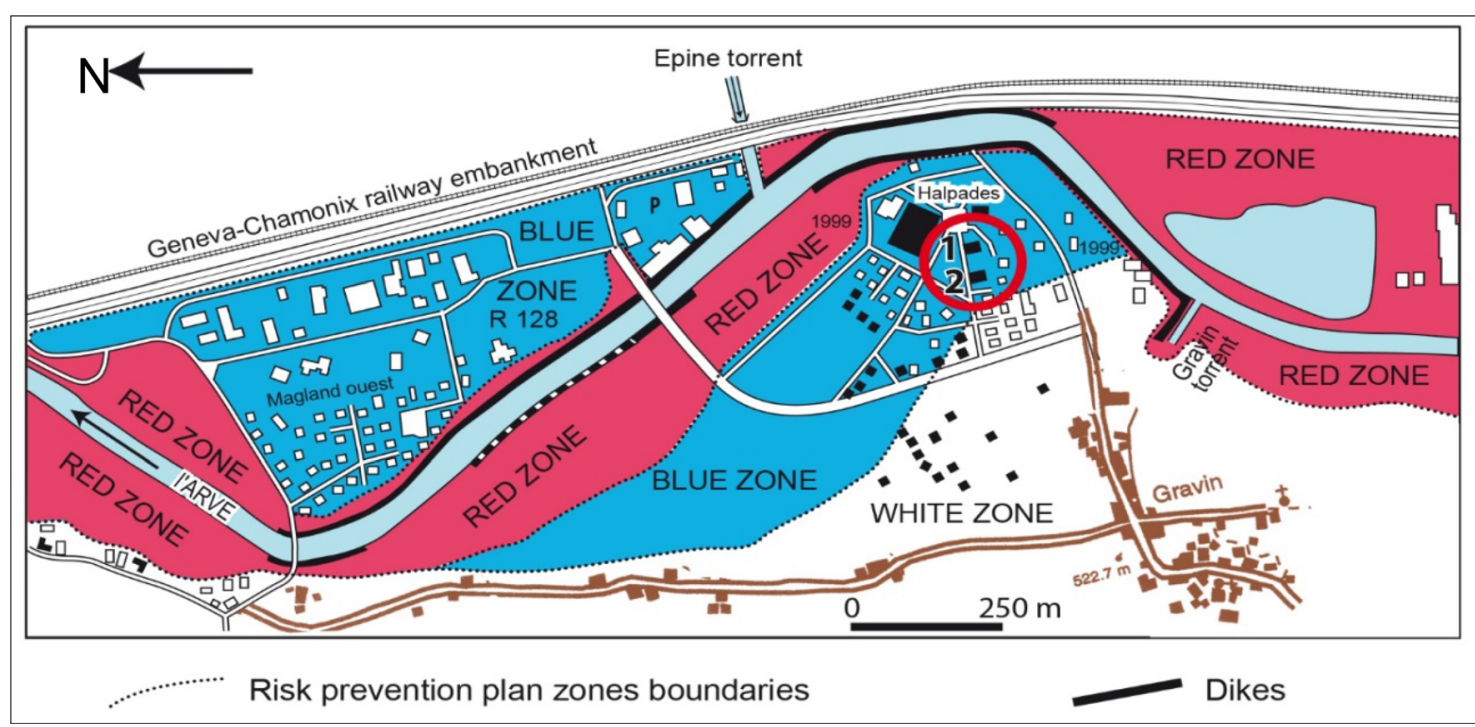

Fig. 1 Location of the two buildings (Fig. 2), encircled in red, on the 1997 Magland risk prevention plan 
Fig. 2 Difference between exposure and vulnerability: two buildings on the Arve River floodplain, Magland Municipality, Northern French Alps a in 1999 and b in 2020 (Photograph by Patrick Pigeon, March 1999 and February 2020)
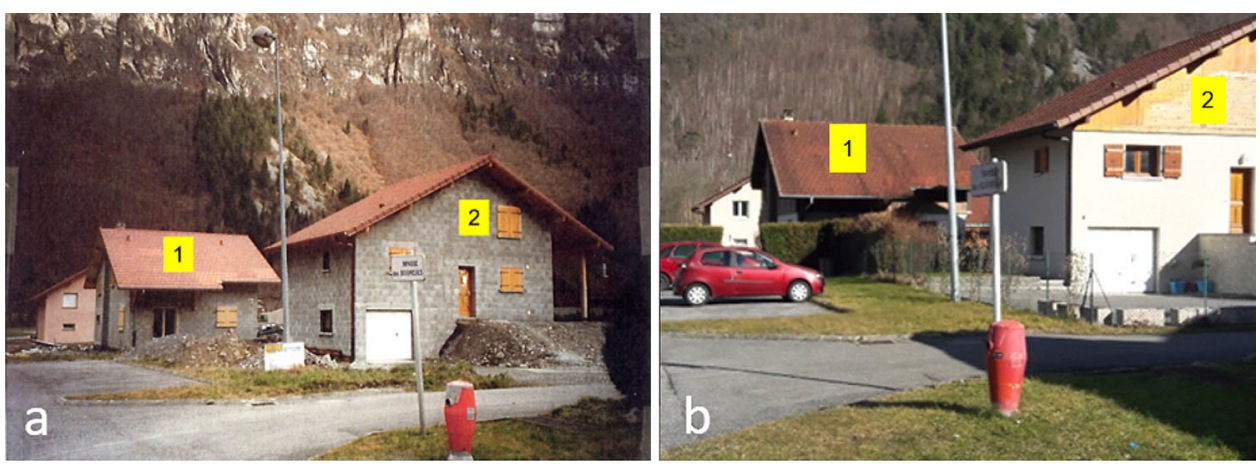

(mainly in Birkmann 2006; Wisner et al. 2012; Nojavan et al. 2018). The main model- the Pressure and Release (PAR) model (Wisner et al. 2004)—has been considered relevant by international institutions, including UNISDR. This does not mean, however, that it is flawless, as shown by its critique over time. The second selected model-the Access model-is an important complement to PAR. The third model - the disaster system identified by Shi and Kasperson (2014)—highlights the difficulties that arise when trying to use systems thinking to produce usable models. The purpose of this article is to emphasize the limits of these three models and to identify why these limits exist-and what the conditions could be to mitigate them.

Numerous models and frameworks (Birkmann 2006) have attempted to address the complexity involved in defining risk, and have stressed the challenges such efforts raise. But all attempts appear to be flawed because they fail to give satisfactory solutions that depict the relationships between hazard, vulnerability, exposure, and capacities. A first weakness relates to the interactions between the basic components of a risk definition before a disaster happens. The second concerns the place devoted to natural hazards in models and in their evolution. Both issues are intimately linked. The rapid evolution of conceptual models acknowledges such limitations and the necessity to find more adequate solutions.

Consideration of conceptual models, in accordance with their evolution, has already been done by Birkmann (2006), but other conceptions have since been introduced by socialecological systems (SES) and the resilience concept of DRR (Cumming 2011; Shi et al. 2013; Rockström et al. 2014). This SES approach is not exactly innovative. Hewitt (1983) already stressed "hazards in context" when referring to the viewpoints of human ecology, while solutions coming from SES were already being investigated by Turner et al. (2003). Recent models go further, yet they still refer to systems without displaying explicit relationships between the basic components of risk definition (Shi and Kasperson 2014).

\subsection{The Pressure and Release Model}

The Pressure and Release (PAR) model (Wisner et al. 2004; Fig. 3), which dates to the first version of At Risk in 1994, partially addressed this issue while integrating capacities into the progression of vulnerability. Yet, relationships between hazard and vulnerability are not explicitly examined. They are presented separately without clear interactions (Fig. 3). Nevertheless, the more recent version of the model does link dynamic pressures and hazards (Wisner et al. 2012). In addition, Wisner et al. (2004) do not refer to hazards as natural, mainly because Wisner and his colleagues consider that disasters result primarily from the structure and evolution of human societies. They stress social root causes or underlying risk factors as the main elements contributing to disasters.

\subsection{The Access Model}

The Access model (Wisner et al. 2004), which complements the PAR model, still contests the relevance of explaining disasters mainly by natural hazards, but clarifies this point (Fig. 4). Hazard takes only the form of a triggering event, as if there was no existing relationship between hazard and vulnerability before the disaster happens.

\subsection{The Disaster System Model}

In some recent models, such as the Disaster System (Fig. 5), relationships between hazard and exposure are mentioned but they are not developed. Yet any system usually refers to a group of factors interacting (Durand 1979). Figure 5 suggests that the researchers resigned themselves to depicting interactions, and even more coevolutions, perhaps because they considered the task almost impossible. 
Fig. 3 The Pressure and Release conceptual model. Source Adapted from Wisner et al. (2004)

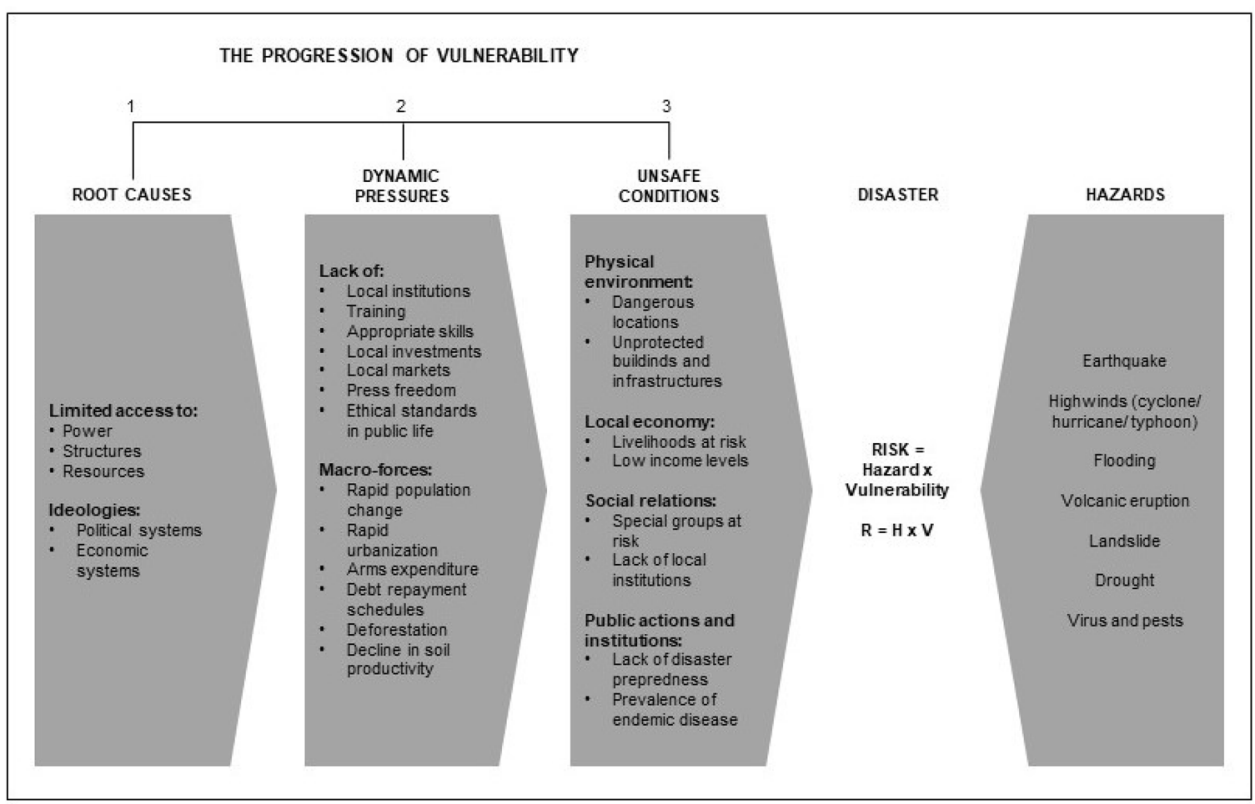

\subsection{Limitations Due to Context Specificity}

Each of the three models has its own specificities and provides a synthetic view of the targeted issue. Their identified limitations are partly due to their context specificity. Despite these limitations, scientific research conducted in parallel with the implementation of DRR policies remains essential for ethical and economic reasons. The goal is therefore to reduce model limitations, even if we are not able to eliminate them completely. It therefore makes sense to propose a more precise model depicting relationships between hazards, exposure, vulnerability, and capacities, where hazard would not necessarily be the first element to appear. A better, more complete model would help further integrate the various components of any international DRR program.

Finally, the evolution of DRR conceptual models draws attention to the limitations they face. Programs that promote DRR are confronted by similar problems. A different institutional context implies that each program and modeller must develop their own solutions when it comes to justifying a structure and representations integrating contributions from earth and social sciences.

\section{Conducting Research Despite Limitations in Existing Conceptual Models}

Despite their differences, GeoRisCA (Georisk in Central Africa) and SF INTERREG (Swiss-French interregional cooperation programme) were chosen to illustrate the interlinked issues such programs have to face. This section therefore compares similar approaches to comparable issues in different contexts.

\subsection{Landslide Risk in Central Africa: Examples from Bukavu City, Democratic Republic of the Congo}

Conceptual model limitations explain why GeoRisCA was confronted with difficulties when its participants sought a framework that could integrate the various contributions on which it relies. The GeoRisCA conceptual model required the integration of different disaster types related to volcanic eruption, landslides, and earthquakes. Volcanic and seismic hazards justify referring to them as natural hazards; they are geodynamic processes not directly or indirectly caused by human activities. Landslides, however, are different. If their assessment needs to take into account natural factors such as lithological and structural landscape characteristics, especially for deep-seated landslides, people can also influence landslide occurrence and dynamics (Sidle and Bogaard 2016).

The city of Bukavu is located in the western branch of the East African Rift, a region naturally prone to landslides (Maki Mateso and Dewitte 2014; Jacobs et al. 2018; Monsieurs et al. 2018; Depicker et al. 2020). Here we focus on three areas in the city studied by GeoRisCA where the risk associated with landslides has increased. Landsliderisk reduction measures are so far absent or inappropriate in these areas (Maes et al. 2017). 


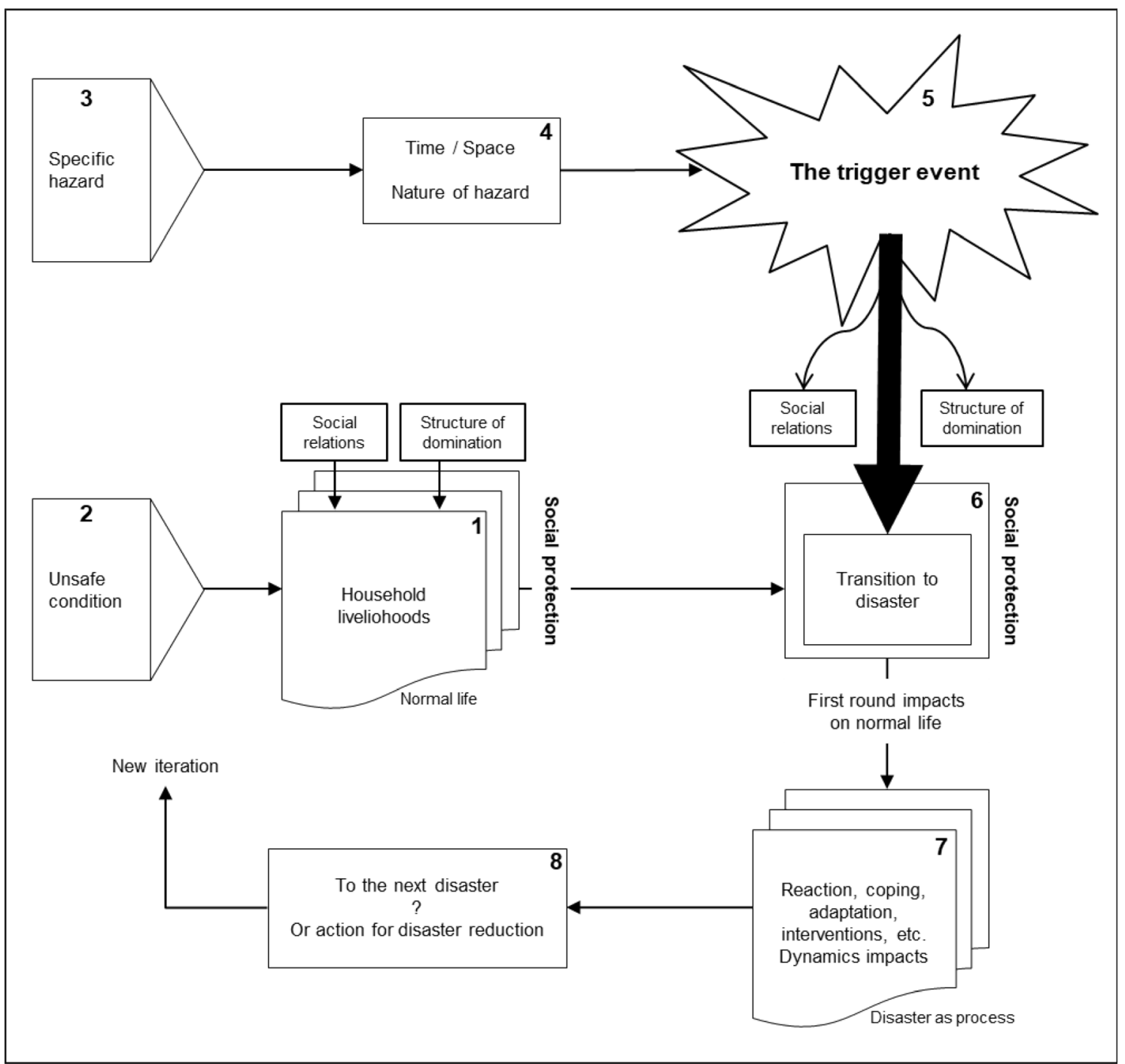

Fig. 4 The Access model. Source Adapted from Wisner et al. (2004)

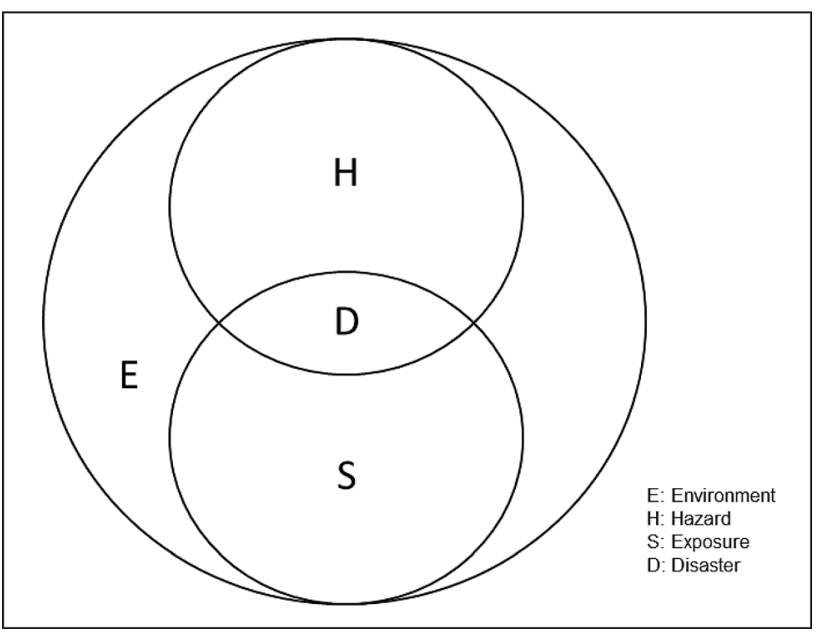

Fig. 5 The Disaster system model. Source Adapted from Shi and Kasperson (2014)

\subsubsection{The Nyakavogo Landslide}

The detailed study of the Nyakavogo landslide indicates that it is an old deep-seated landslide of natural origin (Mugaruka Bibentyo et al. 2017). Historical aerial photographs from 1959 show that, at that time, the landslide area was afforested. The existing ground cover at that time suggests that the topographic and hydrological conditions were not suitable for agriculture.

Beginning in the 1970s, land-use patterns started to change. In 1994, following the genocide in Rwanda (Reyntjens 2009), the occupation of the slope by Rwandan refugees and their needs for wood and garden plots were at the origin of intense deforestation. In 1997, a major reactivation of the landslide took place and affected most of the slope. Within a few months, ground movements with a collapse of up to $15 \mathrm{~m}$ at the main escarpment were 
measured. The collapse destroyed a water pipe located at the top of the landslide. Leakage from the broken pipe dumped water at a rate estimated at $800 \mathrm{~m}^{3} / \mathrm{h}$ for $12 \mathrm{~h}$, accelerating the landslide. Leakage from the pipe before the reactivation is also likely to have played a role in starting the instability. In addition to the damaged water pipe, this movement resulted in the destruction of more than 40 houses, the collapse of electric power poles, and the destruction of the road located behind the original main scarp (Moeyersons et al. 2004). Part of the drainage system of the broken road brought extra runoff to the head of the landslide. Downslope of the slide, the displaced material created a dam in the river flowing at the toe.

Significant forest loss due to cultivation, the increase in the number of houses and related slope earthworks, a concentration of surface runoff at the level of the main escarpment, as well as the intrinsic evolution of the hillslope associated with strength degradation of the slope material through time are all factors that probably contributed to the instability between 1959 and 1997 (Mugaruka Bibentyo et al. 2017; Dille et al. 2019). Subsequently, the natural reorganization of the river after the dam formation and breaching and the erosion accentuated by the exploitation of riverbed materials (stones, gravel, sand) has certainly played an important role in another reactivation that occurred in 2000 , affecting the foot of the landslide.

In 2016, a stabilizing trend was observed. Reforestation in recent years probably played a role. Nevertheless, the recent use of the main scarp as the site for the Bralima landfill, consisting mainly of broken glass bottles, brings an important load to the slope that could reverse this dynamic and affect the houses located at less than $10 \mathrm{~m}$ from the gully. In conclusion, human activity has slowly triggered the reactivation of a large landslide, which has damaged water distribution infrastructure that in turn aggravated the hazard and the associated risk (Fig. 6).

\subsubsection{The Funu Landslide}

The largest landslides of Bukavu, such as the Nyakavogo landslide described above, show morphological characteristics of large deep-seated rotational slides. Some are quite eroded and look old and stable while others seem more recent and have parts that show current deformation activity. Among those landslides stands the largest one $\left(1.5 \mathrm{~km}^{2}\right)$ in the slum neighborhood of Funu (Fig. 7a). This site is densely populated, with around 80,000 people (most of them very poor) living on it (Michellier et al. 2018).

Its origin dates to well before the colonial period. Some parts of the landslide are clearly active with ground deformations of up to several tens of centimeters per year in some places (Nobile et al. 2018). Significant damage to buildings and other infrastructure is constantly observed (Balegamire et al. 2017; Kalikone Buzera et al. 2017). In other areas of the landslide, the dynamics is much more limited, at least in the current period. The canalization of the main brook that runs through the landslide, which dates back to the1950s, was intended to stop the movements of one of its most active parts, and thus allow the construction of brick houses.

However, the work did not hold. At the end of the 1980s, due to progressive house destruction, part of the population was displaced to another district of the city. Trees were planted to try to stabilize the slope. But, from 1994, the population fleeing the genocide in Rwanda and the regional conflicts that followed, settled there. After about 10 years, the displaced population gradually transformed their temporary housing into permanent ones, built mainly from bamboo and clay. The slope, already affected by deformations of the ground due to the dynamics of the
Fig. 6 Reactivation of an old large landslide of natural origin in Bukavu, Democratic Republic of the Congo. The landslide developed much earlier than the construction of the city (Photograph taken by Olivier Dewitte, February 2014). The reactivation is linked to interactions between natural and anthropogenic factors

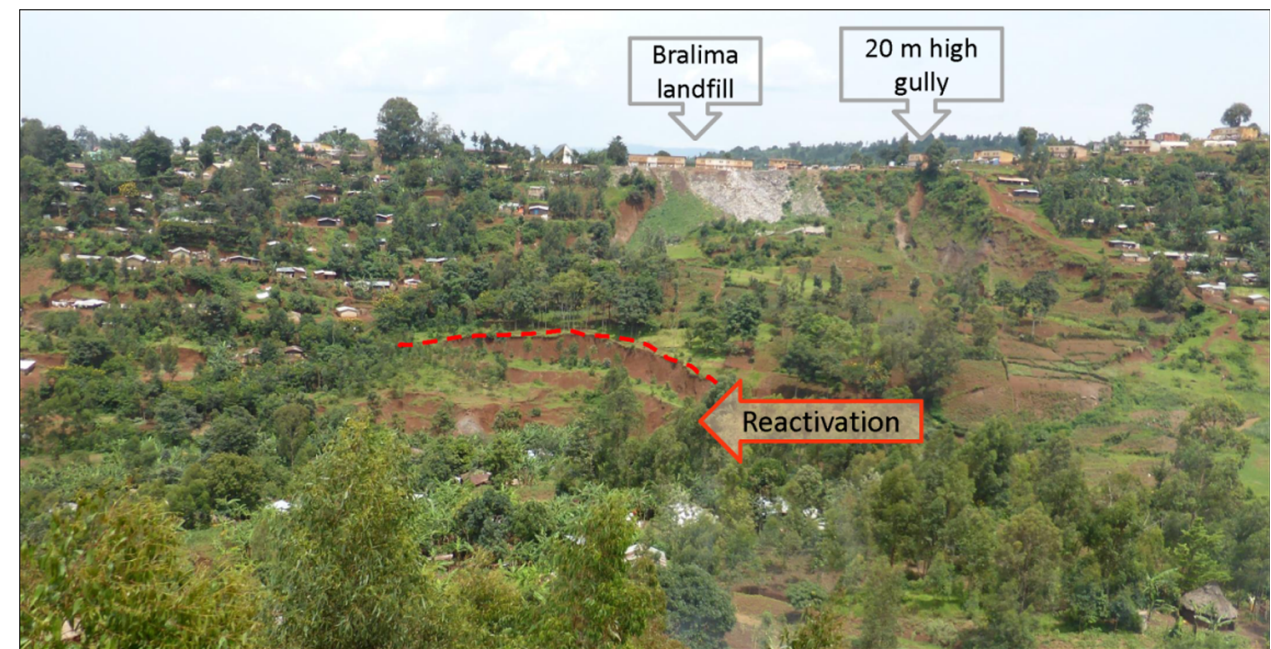




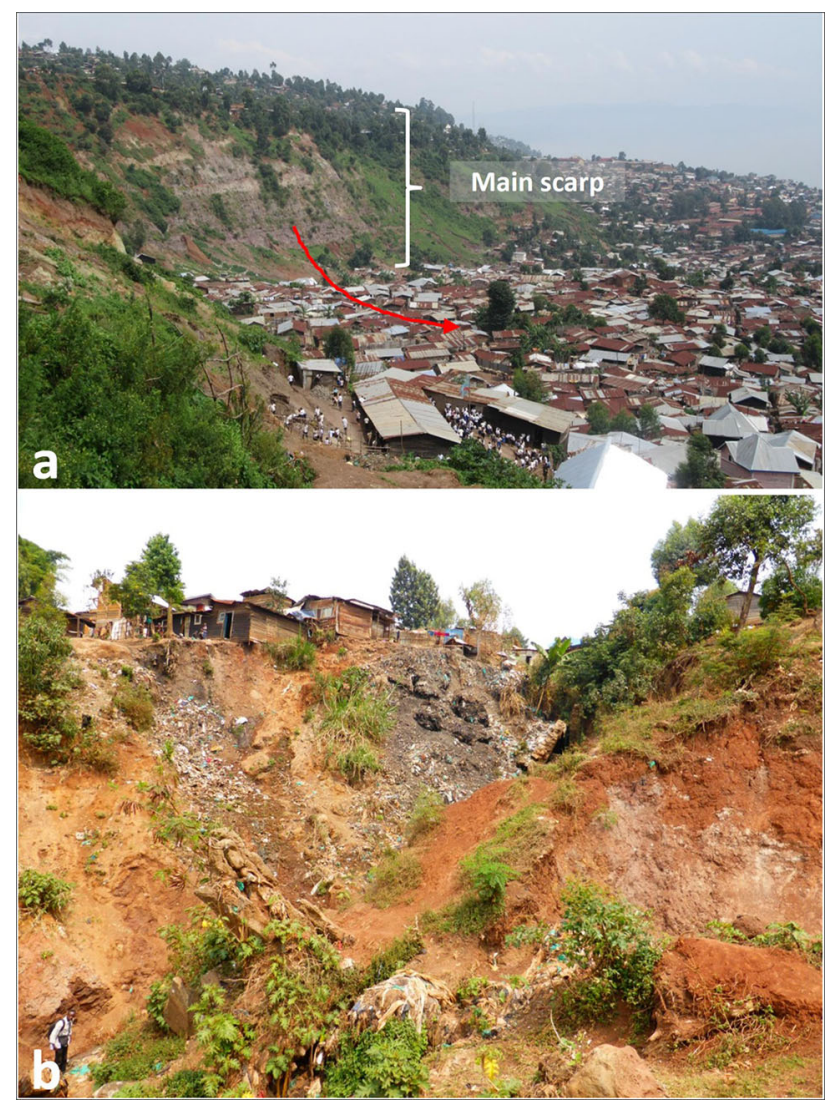

Fig. 7 a View of the largest landslide of Bukavu in the Funu neighborhood (Photograph taken by Olivier Dewitte, August 2015). b Example of a large active gully that develops in the landslide (Photograph taken by Olivier Dewitte, July 2014)

landslide, subsequently underwent a change in land use, with the construction of new buildings replacing forested areas. Tree loss, associated with a strong increase in population, has favored runoff concentration and subsequent infiltration, which led to an additional increase in deformations and gully development.

Water distribution and drainage infrastructure were not maintained, which contributed to additional water concentration. Large gullies originated from the rupture of water network pipes more than 15 years ago (Fig. 7b). These gullies, whose occurrence is also favored by the loose and weakened nature of the displaced material of the landslide, are constantly evolving by the collapse of their slopes; each rainy season brings new instability. The few remaining brick houses date from 1950 to 1955: they withstood deformations and gullying. Today, in this very densely populated area, the more recent houses are constructed with materials adapted to the ground deformation (mainly wood).

\subsubsection{Landslides in the Wesha River Basin}

The third area under review is the Wesha River watershed, with its steep hillsides located at the then western limit of the city (Kulimushi Matabaro et al. 2017). In 1959, the watershed was essentially agricultural: rural habitat was associated with field crops and forests. Food was cultivated annually with other perennial crops, mainly bananas. The banana was a large part of the landscape, some relics of which persist today. Another element of the landscape was large eucalyptus plantations in the mountainous region characterized by average annual temperatures rarely exceeding $20^{\circ} \mathrm{C}$.

In the context of erosion control actions in Kivu (Moeyersons et al. 2004), trees were planted to protect the soil against erosion. Large landslides are present in the watershed. They are old, of natural origin, look stable, and do not seem to represent a constraint on land use (Kulimushi Matabaro et al. 2017). Over the last 60 years, the landscape has changed dramatically. The reduction of the space devoted to agriculture and rural housing is associated with significant population growth. Most of the deforested parts are today densely populated; the landscape is increasingly dominated by unplanned housing with corrugated iron roofs (Fig. 8).

The changes of soil infiltration capacity, and unplanned or unmaintained domestic water drainage structures, favor water concentration. This, in addition to increasing gullying, causes local reactivation of the old landslides. To build houses on the steep slopes, the landscape has been heavily terraced. The resulting slope transformations are usually designed with no or inappropriate retaining structures. This over-steepening of slopes is at the origin of many, rather small landslides that represent a direct danger for

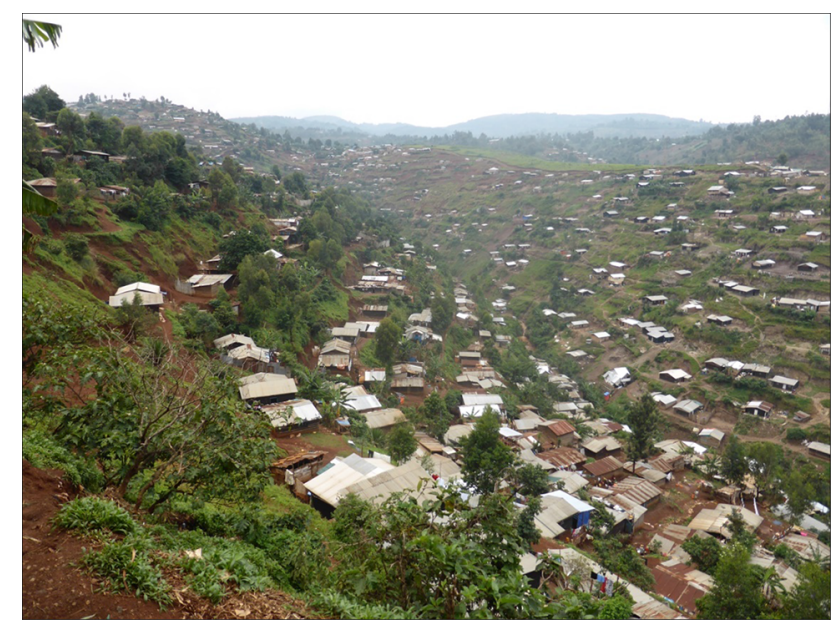

Fig. 8 Densely populated area in the Wesha River basin, Kivu Province. Houses are built on terraces dug into slopes prone to landslides (Photograph taken by Olivier Dewitte, June 2014) 
inhabitants. Catastrophic fatalities recorded in this area are almost all related to this process. These types of landslides are not only present in the Wesha watershed, but also exist on many other steep slopes in the Bukavu region.

\subsubsection{A Unique Conceptual Model?}

These examples illustrate limitations of existing conceptual models. These models should integrate explicitly how hazards and other basic disaster risk components interact. They should also be more dynamic and display feedback loops, in accordance with the situations observed (Gunderson and Holling 2002; Cumming 2011; Rockström et al. 2014; Gill and Malamud 2016; Jacobs et al. 2016). For example, water pipe disruption contributed to the reactivation of landslides and landslides reinforced the disruption of water pipes. The historical process towards the preparation of a disaster could become clearer with a systemic understanding of DRR. The existence of political decisions that concern the location of affected populations and the provision of services, such as water supply, should also be integrated more explicitly into conceptual models.

Representing such complexity is not easy, particularly in a context of data scarcity. Despite attempts to integrate the various components of risk into our equation, we ended up with a simple conceptual model, derived from Wisner et al. (2004), which juxtaposes the basic components of risk, instead of integrating them (Fig. 9). This was the most adequate way to assess the risk due to landslides. Integrating disaster risk prevention policies was not an option because the local institution in charge of disaster prevention and management was too recently established for its work to be evaluated.

\subsection{Assessing Flooding Risk in the Alps: A Very Complex Situation Too}

These examples of conceptual shortcomings are not limited to the African context. The SF INTERREG program faced similar issues (Dupont and Pigeon 2008), although relating to a different hazard. In this case, the Arve mountain river had been fitted with dikes and sills, downstream from the city of Cluses, to prevent flooding (Lopez-Pelaez and Pigeon 2011), especially in the municipality of Scionzier, where we find new economic activity zones (Figs. 10, 11).

Managing floods has contributed to transforming the river itself, and has increased its tendency to damage the existing dikes and sills. As with the GeoRisCA examples, hazards cannot be considered in isolation from exposure, vulnerability, and capacities (Figs. 2, 6). Corrective works such as dikes and sills, which are also significantly referred to as protective works, contribute to transforming not only the source of the hazard (the river), but also the exposed and vulnerable elements (buildings and populations). Hazards, exposed and vulnerable elements, and corrective protective works interact and coevolve. There is therefore a need to find a conceptual model that fits this type of coevolution between hazard and vulnerability before disaster happens. We found none of the existing models met these requirements, so we propose the representation displayed in Fig. 11.

On Fig. 11 the vertical axis-urbanization and corrective work intensification - can bear various values indicating the increasing amount of assets (population, buildings, economic activities, land-use values, and so on) and the increasing number of corrective works (more dikes and sills as time goes on). The vertical axis can also bear the information of increasing trend of river Arve to carve

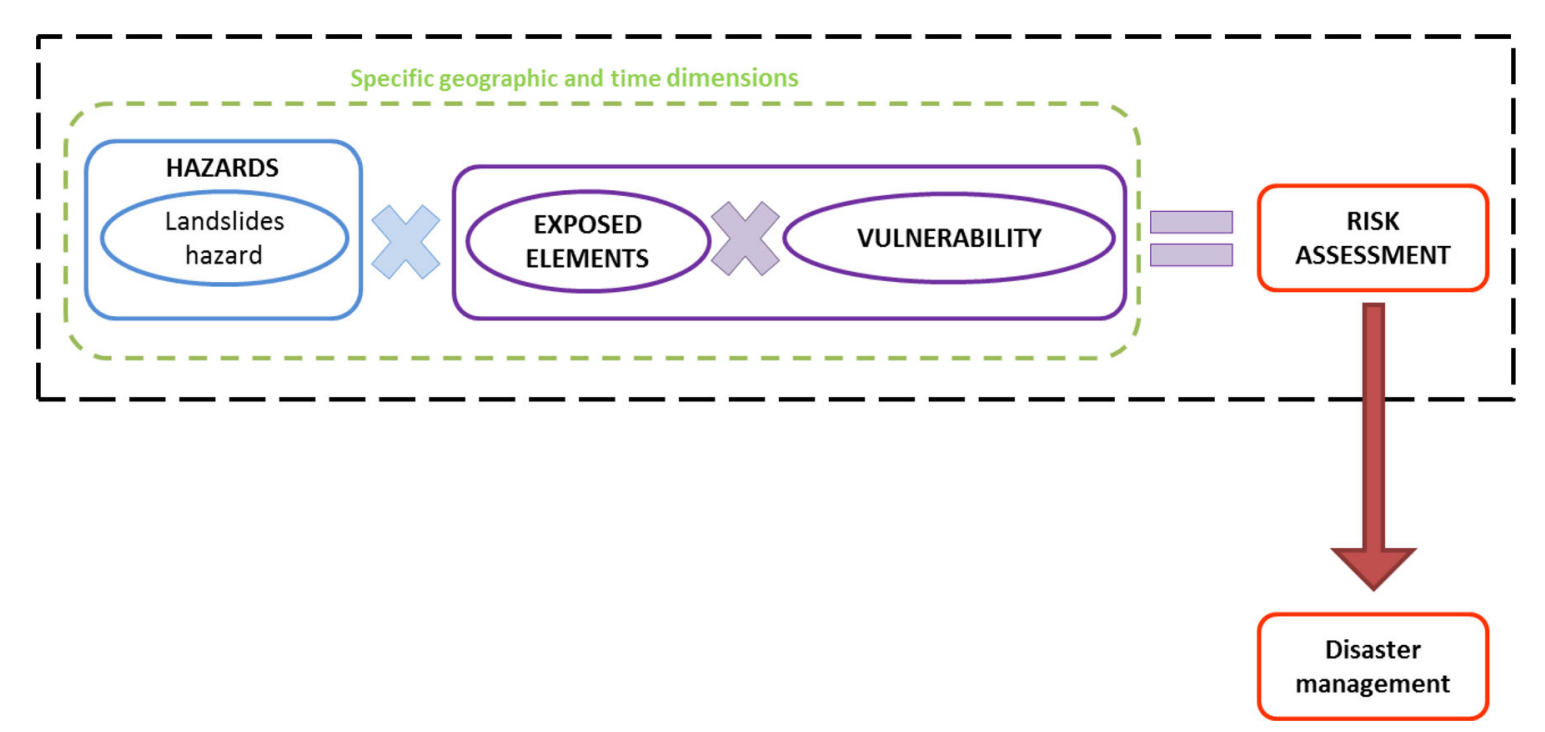

Fig. 9 Conceptual model used in the GeoRisCA project, based on Wisner et al. (2004) 


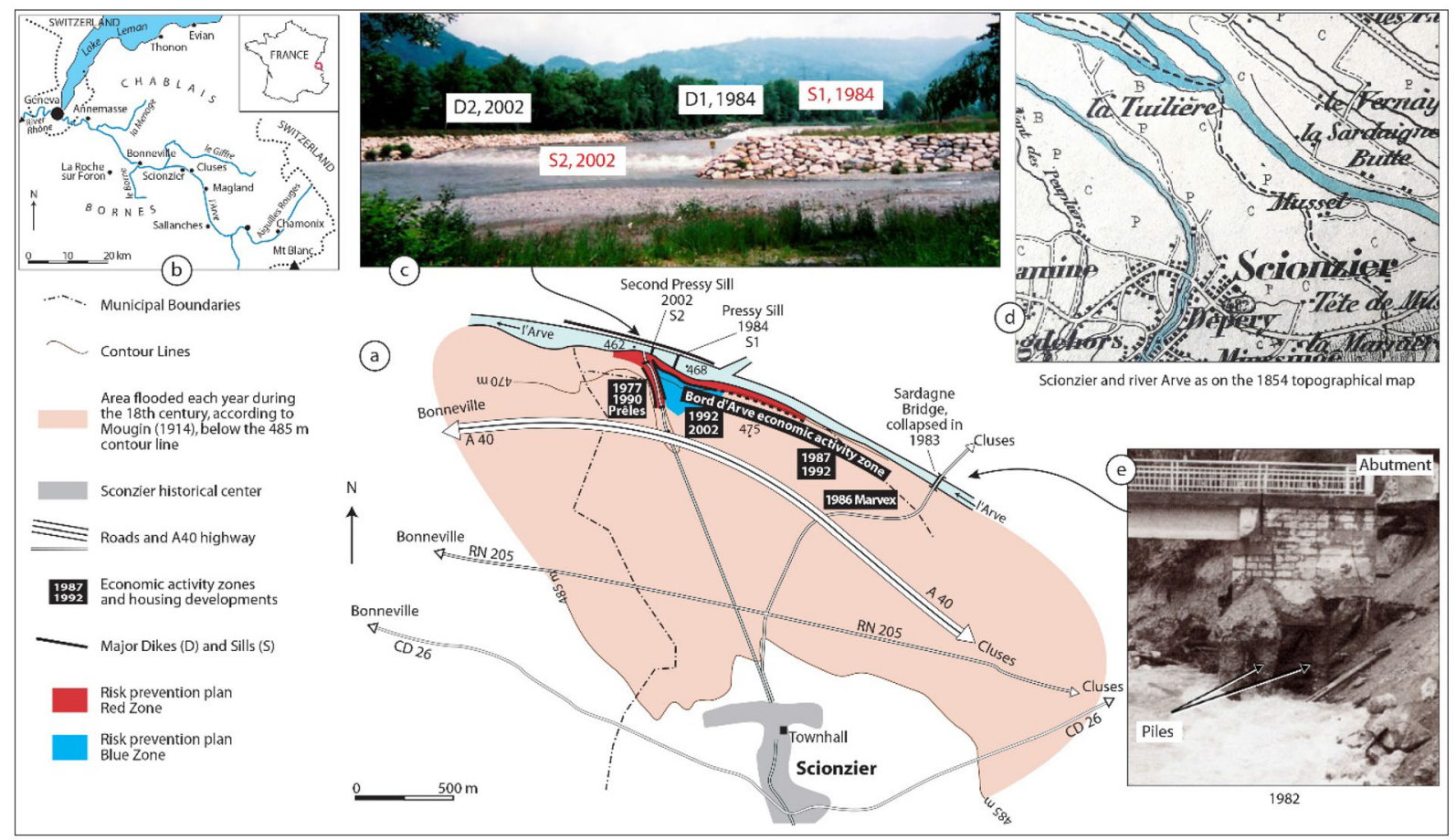

Fig. 10 Location and context of the coevolution model presented in Fig. 11 (a); general map of river Arve valley (b); dikes and sills as reported on map (a, c); Scionzier and river Arve as on the 1854 topographical map (d); Sardagne bridge as in 1982 before its collapse in 1983 (e). Source Archives départementales de Haute-Savoie ("départementales" archives of Haute-Savoie), reference 1 FI 417 for the topographical map of Bonneville, 1854; reference $2478 \mathrm{~W} 173$ for the picture of Sardagne bridge linked with a map at scale $1 / 2000$, 1983

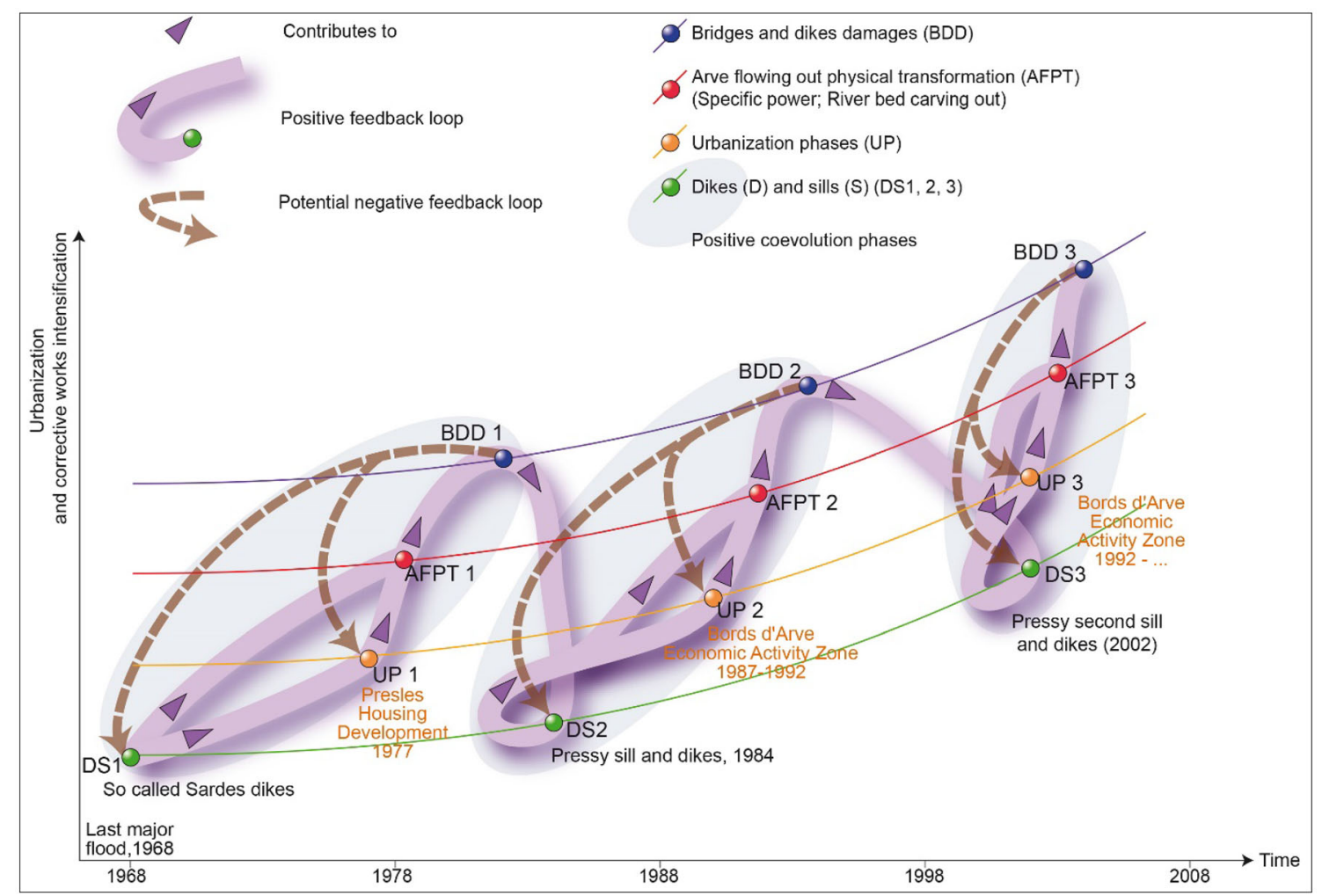

Fig. 11 Representation of coevolutions between hazard (river), exposure, vulnerability (industrial zones), and corrective works (dikes and sills). Source Dupont and Pigeon (2008); Lopez-Pelaez and Pigeon (2011) 
out its bed, therefore incurring more damage to dikes and bridges. This trend is consistent with existing archives on those types of damages. It depicts the general trend towards the preparation for a flood-related disaster for this part of river Arve valley, mostly relying on political decisions made, and on the increased transformation of hazard.

Building more dikes and sills is the trend on the Arve River embankments. These structures contributed to the transformation of the physical characteristics of the mountainous stream by increasing its power. Such an unwanted effect has been investigated by Piegay (1997) on one of the tributaries of the Arve River whose work contributes to explaining why dikes and bridges are being regularly damaged, if not totally destroyed, by the river carving out its bed at the expense of surficial deposits. This effect has also been investigated and measured (Peiry et al. 1994). In 1983, the well documented trend led to Sardagne bridge collapse (Fig. 10e). Following damage to dikes and sills, the response of local authorities was to repair dikes and build additional corrective protective infrastructure.

In this case, the river represents the hazard: the dikes can be considered as exposed and vulnerable elements, because they are regularly damaged. Dikes cannot be justified without integrating capacities and political decisions to construct them into the model. River and dikes cannot be seen as independent risk factors, which is the case with the PAR conceptual model. First, it would be incorrect to consider a diked-up river as a natural hazard. If the trend for the Arve River to carve its bed reveals the existence of surficial Quaternary and post-Würm deposits, it cannot alone explain this trend. If this were the case, the Arve would have deepened its bed earlier because some of it has been channelized since the nineteenth century (by the socalled "Sardes" dikes, before the annexation of this part of Savoy by France in 1860). Quaternary deposits play a role in the process, among other risk factors, and should be considered as an element of a wider hydrologic system. These deposits reveal how natural heritage also needs to be integrated in conceptual models.

The coevolution is not limited to rivers and dikes in this example. Municipal archives have helped identify and illustrate the coevolution that has taken the form of two feedback loops (Fig. 11) involving hazard (river) and exposed elements (corrective works and new buildings, mainly industrial zones in Cluses). Damage to former corrective infrastructures justified two new periods of preventive construction: in 1984 and 2002, which, in turn, transformed the river-and the hazard-even more. As protective and corrective infrastructures, dikes favored more investment and buildings behind them. In turn, the necessity to protect an increased number of industrial estates behind the newly-built dikes was not contested by the municipality.
A positive feedback loop happens when the decision is made to strengthen the existing elements: dikes, economic activity zones, housing developments. This feedback loop unwillingly prepares a disaster because of the increasing amount of assets on a still flood-prone area. A negative feedback loop would happen if the decision would have been to let river Arve destroy the existing dikes-Fig. 11 depicts with dashed lines a possible negative feedback loop, which was not implemented following political decisions. This new trend would contribute to preventing a flood-related disaster, because of the reduced amount of assets on an unprotected flood-prone area. In our example, the decision taken for areas already built was to protect the area even more.

Dikes and rivers coevolve with time, and this coevolution is related to risk and risk management. If the time scale is extended, and the flooding history of the region is taken into account (Mougin 1914), this historical perspective highlights the transition of this area from high flood frequencies towards potentially stronger damage intensities, for instance in case of dike failures. It justifies even more the need to display this unwanted coevolving trend.

Such perceived preventative measures lead people to think that the targeted risk is reduced, and that settlements on (former but still) risk-prone areas is possible. Such an understanding challenges the relevance of referring to rivers or landslides as natural hazards, as well as considering human societies as purely passive. This led to the need to address more holistically the issue of water or landslide management and understanding, using a socialecological systems (SES) approach. In SF INTERREG, local case studies refer to SES representation, and address specifically coevolutions between different risk components like hazard, vulnerability, and corrective protective measures (Fig. 11; Dupont and Pigeon 2008). However, the SF INTERREG project refrained from upscaling such a representation, and did not attempt to propose a new conceptual model, such as, for example, in Rockström et al. (2014), because it would have been almost impossible to create an operating model in disaster risk prevention, either for managers or scientists.

Although strong commonalities exist between programs as different as GeoRisCA and SF INTERREG, both turned towards DRR, having the possibility to rely on a conceptual model would have greatly helped presenting and justifying them. But no existing conceptual model fitting their needs could be identified. Therefore, we had to contextualize definitions and models. It therefore makes sense to reconsider the conceptual models above, to investigate further and to summarize why we were confronted by such shortcomings. In other words, why cannot existing 
conceptual models adequately respond to the needs of international programs such as GeoRisCA or SF INTERREG?

There is one more point concerning the relevance of comparing DRR programs with a focus on very culturally and physically different areas that can be made. Since disasters such as Hurricane Katrina in 2005, international literature on DRR acknowledges that common points are more relevant than discrepancies between least developed countries and more developed countries (Wisner et al. 2012). This is one of the major points revealed by the Sendai Framework for Disaster Risk Reduction 2015-2030, in accordance with a wide range of international research (UNISDR 2015). The most critical issues are linked to the difficulties of reducing socioeconomic discrepancies and taking into account power relationships, which are considered, by far, the most important drivers of disaster-and not only in the least developed countries.

\section{Discussion: What Are the Main Difficulties Faced by Conceptual Models on Disaster Risk Reduction?}

Our results allow us to argue that conceptual models have to clearly and comprehensively depict basic risk definition components, in line with reference definitions concerning DRR and risk. Doing so, however, means that conceptual models might challenge mainstream views.

We found an increased recognition that hazards can no longer be considered as purely natural factors impacting passive and vulnerable human societies (Pigeon 2002; Gill and Malamud 2017). This traditional understanding generally refers to natural hazards and disasters. But existing literature on DRR suggests that it belongs to an older approach (Garcia-Acosta 2005; UNISDR 2015). A wide range of corrective and protective measures, such as dikes and drainage networks, clearly transform hazards by integrating them into social-ecological systems.

Natural hazards also have a role to play when assessing and preventing disasters due to earthquakes or volcanic eruptions, which requires careful monitoring. For example, deep-seated earthquakes reveal geodynamics of the lithosphere in rift and subduction zones. They cannot be influenced by human beings and their activities. But humankind still has the possibility to transform hazards and their impacts locally, while using seismic building codes, or not building on sites where surficial deposits are found, for example. Such discrepancies justify why DRR conceptual models should still clearly integrate natural hazards and the possibilities for human beings to manage hazards by interacting with them.
According to our analysis, the limitations of conceptual models stem mainly from the difficulty of clearly addressing the relationships between hazards and other basic components of disaster risk definition before the disaster occurs. This situation is exacerbated by the increasingly blurred place devoted to "natural hazards" in recent models, as if the focus of an earthquake related with lithosphere geodynamics could be similar to a landslide reactivated by human activities. On the contrary, they should be considered as distinct components of larger systems depicting risk and disaster dynamics (Baccini and Brunner 2012; Pigeon 2002, 2005, 2014).

Systemic and social-ecological system (SES) approaches may help to find solutions (Gunderson and Holling 2002). However, SES conceptual models may also reduce the visibility of the relationships between hazards and other basic components of disaster risk definition in programs such as GeoRisCA and SF INTERREG. In addition, SES tends to eliminate the still-existing contribution of natural hazards to the understanding of disasters preparation. Even reduced, this place should not be removed from the existing conceptual models (Pigeon 2002).

DRR conceptual models should also represent how those components that frame risk do interact and coevolve, while leaving room for some natural hazards that do not interact with vulnerability factors before a disaster occurs. Depicting clearly and comprehensively such paradigms challenges traditional and systemic conceptual models.

Coevolution between hazards and other basic components of disaster risk can be represented by using spirals to illustrate feedback loops: this helps to describe trends towards disasters on the one hand and how local choices can contribute-or not-to disaster prevention on the other. To achieve such a representation requires accessing and using various archives, documents, and data, allowing the cross-referencing of existing information. It also needs existing knowledge and experience on past policies and their limitations. Of course, it would be very difficult to find similar information for a program such as GeoRisCA. Geopolitical unrest and poverty exacerbate the challenge of turning to DRR conceptual models.

However, the use of spirals in future conceptual models on disaster prevention could be investigated. Spirals could clearly depict how hazards change over time, as they interact with other risk components. Spirals describe feedback loops, and hazards become elements contributing to those feedback loops. Such representations should fit the need to reconsider how to understand risk at the beginning of the Anthropocene. The representation we propose (Figs. 11, 12), even though contextualized, could be a first step in that direction.

Based on these evaluations of both programs, a representation of relationships between hazards and other basic 
Fig. 12 Evolving conceptual model. Source Adapted from Pigeon (2002)

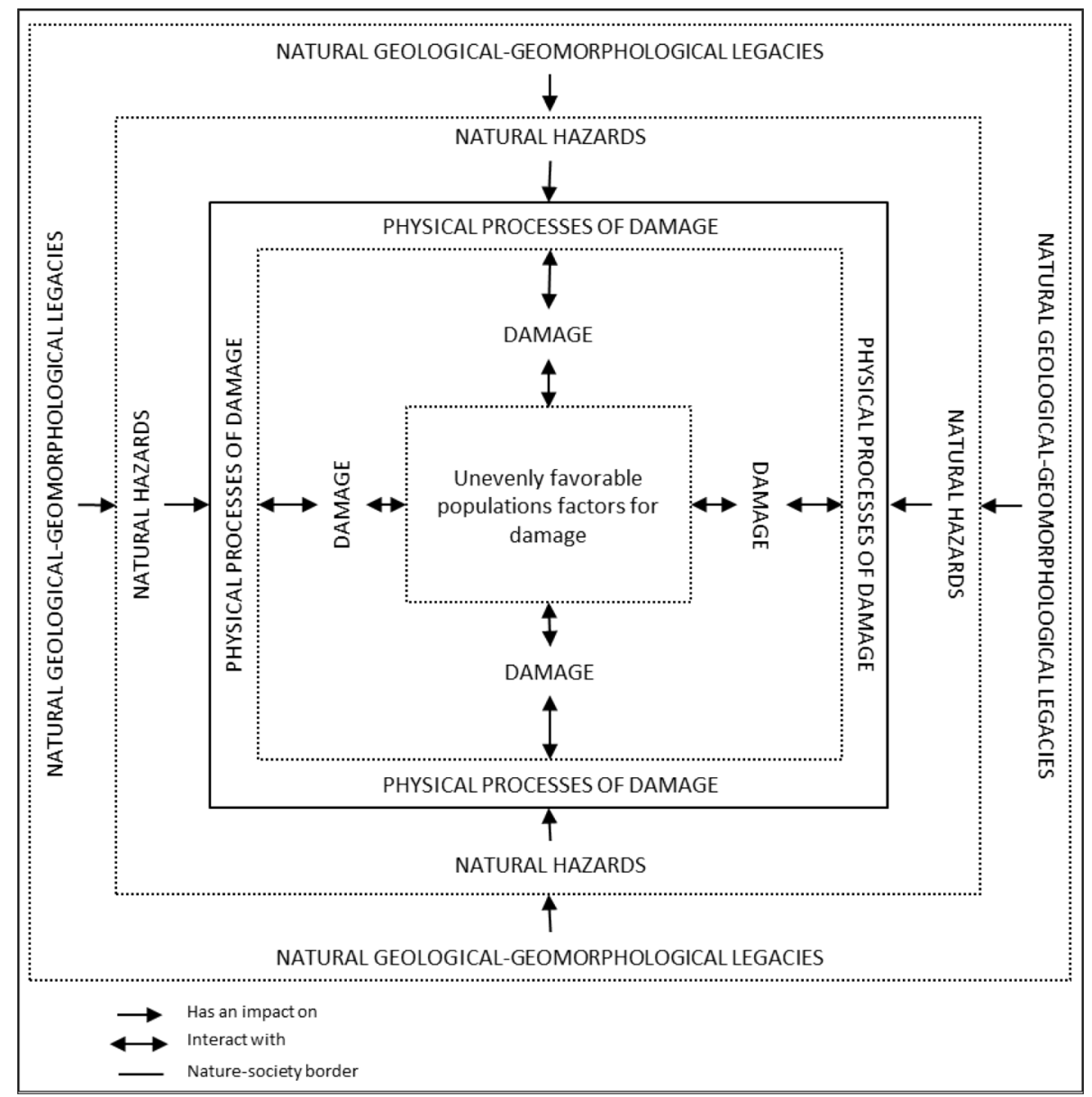

components of the disaster risk definition could be proposed, and used as a trade-off between existing models to harmonize the needs of programs such as GeoRisCA or SF INTERREG. According to our analysis, any conceptual model on DRR should distinguish between natural heritage, natural hazards, and hazards by integrating the human capacity to transform the environment, willingly or not. Yet, representing the dynamics of partial coevolutions across such a wide range of components that underpin the definitions of any disaster remains a challenge. The debate is not recent: it has been addressed by researchers who specialize in complexity such as Morin (2010) and Dupuy (2002) and even by philosophers focusing on knowledge such as Bergson (1934). Figure 12 (Pigeon 2002) presents a conceptual model that attempts to address these concerns: it distinguishes between natural hazards and hazards that are transformed, willingly or not, by decisions made by human societies, and which are named physical processes.

On Fig. 12, the nature-society boundary marks the limit between the natural environment of the system, including natural hazards and the risk system. The latter is identifiable by the dynamic interactions between physical damage processes (hazards) and exposed elements preparing damage, their vulnerabilities depending on political decisions that coping capacities refer to. This interpretation is imposed by the fact that both the distribution and the forms of damage are partially conditioned by the legacies of geomorphological evolution, as well as by the fact that plate tectonics escape anthropization. The recognition of Anthropocene reduces the relevance of the nature-society boundary, and challenges it, without allowing to eliminate it.

Finally, DRR conceptual models should integrate a dynamic and more consistent approach concerning the place devoted to hazards. However, Fig. 12 is clearly not dynamic enough because it does not depict any feedback loop and it has not been contextualized, compared to Fig. 11. A trade-off between these two conceptual models is still needed. Figure 11 is more contextualized, more operational, yet highly context-dependent; while Fig. 12 is less contextualized, less operational, and therefore fits more the holistic approach that is expected from any conceptual model. 


\section{Conclusion}

The comparison between GeoRisCA and SF INTERREG reveals the difficulty of integrating more contributions coming from earth and social sciences into DRR conceptual models. This is not an original observation. One of the authors had the opportunity to contribute to five other international programs, in various countries including Sri Lanka and Germany. In each case, this difficulty of finding a more consistent conceptual model for framing the programs arose.

Such a situation draws attention to some major limitations that conceptual models on DRR still meet. They reflect the lack of consensus in defining disaster and disaster risk, based on the understanding of the relationships between its four basic components: hazard, exposure, vulnerability, and capacities. The existing literature on disasters has addressed and still addresses this hotly debated issue. According to Collins (2018, p. 494), "less progress has been made in addressing complex intersections of environmental systems, power, and cultures that underlie emergent understanding of the nature of risk reactions and active engagement." Similar discussions have arisen concerning the notion of resilience, which is today considered key in disaster studies, despite debates around its various perceptions, some of them being contradictory (Pigeon 2014, 2016).

Furthermore, these difficulties are also related to the challenge of representing relationships between the four basic components of disaster risk. This challenge explains the rise of SES thinking (Gunderson and Holling 2002; Shi et al. 2013). Yet, all these models fail to address clearly and comprehensively the existing interactions identified, as well as their evolution. Understanding, assessing, and preventing disasters require a dynamic approach. The increased recognition that disasters emerge largely from the inside of human societies and reflects their dynamics is a trend. Consequently, divergences between Western Europe and Africa are diminished. Poverty and power relationships are of course context-specific, but they play a major role in understanding and managing disasters (Maes et al. 2018). As stressed by the UNISDR (2015), issues related to poverty and power relationships are common to all countries and are the main drivers of disasters. Addressing them is considered key by UNISDR 2015 and the Sendai Framework.

A particularly sensitive priority relates to the place devoted to hazards in these conceptual models. Socialecological system thinking is consistent with the need to integrate into disaster understanding the capacity of human societies to transform their environment. However, whether with GeoRisCA or SF INTERREG, or other international programs, it seems unlikely to assess disasters without taking into account natural elements and/or elements that are unalterable by humankind. In the Democratic Republic of the Congo, most earthquakes are still related to the geodynamics of African rifting. A river such as the Arve can deepen its bed not only because it has been diked (among various other factors impacting this process), but also because of the geological and natural characteristics of surficial, post-glacial deposits.

Finally, DRR conceptual models should more explicitly integrate the existing relationships between natural hazards, human-transformed hazards, and such other risk factors as exposure, vulnerability, and preventive policies. Such models should no longer present hazards first. Yet, such models would still integrate hazards into a dynamic process, socially and politically driven, eventually leading to a disaster. As Collins (2018, p. 487) wrote: "Though much of the field has been, and often continues to be, analysed from a natural-hazards orientation, a significant drive has shifted the paradigm to be people centred through more socially, politically, economically, and culturally aware agendas." But where is the conceptual model that deals with this shift? Finding a solution would greatly help presenting and justifying the structures of international programs on DRR. Disaster risk reduction conceptual models are also too static to depict the trends towards disasters and the possibility of preventing them. It is possible to represent coevolution between risk factors such as hazards, vulnerability, and exposure that prepare disasters, including coping capacities, but only from local case studies. In conclusion, scaling-up these representations using a dynamic conceptual model as a tool to support local DRR decision making remains a challenge.

Acknowledgements This article highlights the results of two different research projects: (1) the GeoRisCA project (Contract No. SD/ $\mathrm{RI} / 02 \mathrm{~A}$ ) financed by the program "Science for Sustainable Development" of the Belgian Science Policy; and (2) the SF INTERREG program (Swiss-French interregional cooperation programme) cofinanced by the European Union and the Swiss Confederation. Special acknowledgment to Clarisse Baligamire, Toussaint Mugaruka Bibentyo, Antoine Dille, Christian Kalikone Buzera, Sylvain Kulimushi Matabaro, Elise Monsieurs for their helpful discussions.

Open Access This article is licensed under a Creative Commons Attribution 4.0 International License, which permits use, sharing, adaptation, distribution and reproduction in any medium or format, as long as you give appropriate credit to the original author(s) and the source, provide a link to the Creative Commons licence, and indicate if changes were made. The images or other third party material in this article are included in the article's Creative Commons licence, unless indicated otherwise in a credit line to the material. If material is not included in the article's Creative Commons licence and your intended use is not permitted by statutory regulation or exceeds the permitted use, you will need to obtain permission directly from the copyright holder. To view a copy of this licence, visit http://creativecommons. org/licenses/by/4.0/. 


\section{References}

Aitsi-Selmi, A., V. Murray, C. Wannous, C. Dickinson, D. Johnston, A. Kawasaki, T. Stevance, and T. Yeung. 2016. Reflections on a science and technology agenda for 21 st century disaster risk reduction. International Journal Of Disaster Risk Science 7(1): $1-29$.

Baccini, P., and P.H. Brunner. 2012. Metabolism of the anthroposphere: Analysis, Evaluation, Design. Cambridge, MA: MIT Press.

Balegamire, C., C. Michellier, J.B. Muhigwa, D. Delvaux, G. Imani, and O. Dewitte. 2017. Vulnerability of buildings exposed to landslides: A spatio-temporal assessment in Bukavu (DR Congo) (Vulnérabilité du bâti face aux glissements de terrain:analyse spatio-temporelle à Bukavu [RD Congo]). Geo-Eco-Trop 41(2): 263-278 (in French).

Bergson, H. 1934. Introduction to metaphysics (Introduction à la métaphysique). Paris: Presses Universitaires de France.

Birkmann, J. 2006. Measuring vulnerability to natural hazards: Towards disaster resilient societies. Tokyo: United Nations University Press.

Birkmann, J., and B. Wisner. 2006. Measuring the un-measurable: The challenge of Vulnerability. Report of the second meeting of the UNU-EHS expert working group on measuring vulnerability, 12-14 October 2005, Bonn, Germany. Institute for Environment and Human Security, United Nations University.

Blaikie, P., T. Cannon, I. Davis, and B. Wisner. 1994. At risk: Natural hazards, people's vulnerability and disasters. New York: Routledge.

CRED (Centre for Research on the Epidemiology of Disasters). 2015. EM-DAT international disaster database. https://www.emdat.be/ . Accessed 27 Mar 2020.

Collins, A.E. 2018. Advancing the disaster and development paradigm. International Journal of Disaster Risk Science 9(4): 486-495.

Cumming, G.S. 2011. Spatial resilience in social-ecological systems. Dordrecht: Springer.

Cutter, S.L., L. Barnes, M. Berry, C. Burton, E. Evans, E. Tate, and J. Webb. 2008. A place-based model for understanding community resilience to natural disasters. Global Environmental Change 18(4): 598-606

Depicker, A., L. Jacobs, D. Delvaux, H.-B. Havenith, J.-C. Maki Mateso, G. Govers, and O. Dewitte. 2020. The added value of a regional landslide susceptibility assessment: The western branch of the East African Rift. Geomorphology 353: Article 106886.

Dille, A., F. Kervyn, T. Mugaruka Bibentyo, D. Delvaux, G. Bamulezi Ganza, G. Mawe Ilombe, C. Kalikone Buzera, et al. 2019. Causes and triggers of deep-seated hillslope instability in the tropics-Insights from a 60-year record of Ikoma landslide (DR Congo). Geomorphology 345: Article 106835.

Duncan, D., S. Scherer, and S. Wade-Apicella. 2014. HFA thematic review: Research area 2, priority for action 3, core indicator 1 . Background paper prepared for the global assessment report on disaster risk reduction 2015. Geneva, Switzerland: UNISDR. https://www.preventionweb.net/english/hyogo/gar/2015/en/ bgdocs/UNISDR,\%202014c.pdf. Accessed 16 Dec 2019.

Dupont, C., and P. Pigeon. 2008. Rhône River upper montainous watershed: Towards an integrated management of transboundary territories (Le Haut-Rhône et son bassin versant montagneux: pour une gestion intégrée des territoires transfrontaliers). Le Bourget-du-Lac: Institut de la Montagne, Université de Savoie (in French).

Dupuy, J. 2002. For enlightened catastrophism (Pour un catastrophisme éclairé). Paris: Le Seuil.
Durand, P. 1979. Systemic (La systémique). Paris: Presses Universitaires de France.

Fekete, A., and G. Hufschmidt. 2016. Atlas of vulnerability and resilience: Pilot version for Germany, Austria, Liechtenstein and Switzerland. Köln and Bonn: TH Köln and University of Bonn.

Fra Paleo, U. 2019. Timescape of disaster risk governance in contemporary Japan: Neither state of normalcy nor constancy in regulation. PLOS ONE 14: 1-16.

Garcia-Acosta, V. 2005. Risk as a social construct and the social construction of risk (El riesgo como construcción social y la construcción social de riesgos). Desacatos: Revista de Ciencias Sociales 19: 11-24 (in Spanish).

Gill, J.C., and B.D. Malamud. 2016. Hazard interactions and interaction networks (cascades) within multi-hazard methodologies. Earth System Dynamics 7(3): 659-679.

Gill, J.C., and B.D. Malamud. 2017. Anthropogenic processes, natural hazards, and interactions in a multi-hazard framework. EarthScience Reviews 166: 246-269.

Guillier, F. 2017. French insurance and flood risk: Assessing the impact of prevention through the rating of action programs for flood prevention. International Journal of Disaster Risk Science 8(3): 284-295.

Gunderson, L.H., and C.S. Holling. 2002. Panarchy: Understanding transformations in human and natural systems. Washington, DC: Inland Press.

Hewitt, K. 1983. Interpretations of calamity. Boston: Allen and Unwin.

Jacobs, L., O. Dewitte, J. Poesen, J. Sekajugo, A. Nobile, M. Rossi, W. Thiery, and M. Kervyn. 2018. Field-based landslide susceptibility assessment in a data-scarce environment: The populated areas of the Rwenzori Mountains. Natural Hazards and Earth System Sciences 18: 105-124.

Jacobs, L., J. Maes, K. Mertens, J. Sekajugo, W. Thiery, N.N. van Lipzig, J. Poesen, M. Kervyn, and O. Dewitte. 2016. Reconstruction of a flash flood event through a multi-hazard approach: Focus on the Rwenzori Mountains, Uganda. Natural Hazards 84(2): 851-876.

Kalikone Buzera, C., F. Teganyi, O. Dewitte, and C. Michellier. 2017. Ground deformation impact on the vulnerability of water and electricity distribution networks in Bukavu (DR Congo). GeoEco-Trop 41(2): 279-292.

Kelman, I. 2018. Lost for words amongst disaster risk science vocabulary? International Journal of Disaster Risk Science 9(2): 281-291.

Kulimushi Matabaro, S., T. Mugaruka Bibentyo, W. Muhindo Sahani, C. Michellier, and O. Dewitte. 2017. Landslides and elements at risk in the Wesha watershed (Bukavu, DR Congo). Geo-EcoTrop 41(2): 233-248.

Lewis, J. 1999. Development in disaster-prone places: Studies of vulnerability. London: Intermediate Technology Publications.

Lewis, J. 2011. Corruption: The hidden perpetrator of underdevelopment and vulnerability to natural hazards and disasters. Jamba: Journal of Disaster Risk Studies 3(2): 464-475.

Lopez-Pelaez, J., and P. Pigeon. 2011. Co-evolution between structural mitigation measures and urbanization in France and Colombia: A comparative analysis of disaster risk management policies based on disaster databases. Habitat International 35(4): 573-581.

Maes, J., M. Kervyn, A. de Hontheim, O. Dewitte, L. Jacobs, K. Mertens, M. Vanmaercke, L. Vranken, and J. Poesen. 2017. Landslide risk reduction measures. Progress in Physical Geography: Earth and Environment 41(2): 191-221.

Maes, J., C. Parra, K. Mertens, B. Bwambale, L. Jacobs, J. Poesen, O. Dewitte, L. Vranken, et al. 2018. Questioning network governance for disaster risk management: Lessons learnt from 
landslide risk management in Uganda. Environmental Science \& Policy 85: 163-171.

Magny, M. 2019. Origins of the Anthropocene: Ecological crisis mirroring a crisis of humankind (Aux racines de l'anthropocène; Une crise écologique reflet d'une crise de l'homme). Lormont, France: Le bord de.l'eau (in French).

Maki Mateso, J.-C.I., and O. Dewitte. 2014. Towards an inventory of landslide processes and the elements at risk on the Rift flanks west of Lake Kivu (DRC) (Vers un inventaire des glissements de terrain et des éléments à risque sur les versants du Rift à l'ouest du Lac Kivu (RDC)). Geo-Eco-Trop 38(1): 137-154.

Menoni, S., and C. Margottini. 2011. Inside risk: A strategy for sustainable risk mitigation. Berlin: Springer.

Michellier, C., D. Delvaux, O. Dewitte, N. D’Oreye, H.-B. Havenith, M. Kervyn, S. Poppe, B. Smets, et al. 2018. Geo-risk in central Africa: Integrating multi-hazards and vulnerability to support risk management. Brussels: Belgian Earth Obervation.

Moeyersons, J., P. Tréfois, J. Lavreau, D. Alimasi, I. Badriyo, B. Matima, M. Mundala, D.O. Munganga, et al. 2004. A geomorphological assessment of landslide origin at Bukavu, Democratic Republic of the Congo. Engineering Geology 72(1): 73-87.

Monsieurs, E., L. Jacobs, C. Michellier, J. Basimike Tchangaboba, G. Bamulzi Ganza, F. Kervyn, J.-C. Maki Mateso, T. Mugaruka Bibentyo, et al. 2018. Landslide inventory for hazard assessment in data-poor context: A regional-scale approach in Central Africa. Landslides 15(11): 2195-2209.

Morin, E. 2010. Introduction to complex thinking (Introduction à la pensée complexe). Paris: Points.

Mougin, P. 1914. Montainous rivers of Savoy (Les torrents de la Savoie). Chambéry: Savoy Natural History Society, Société d'Histoire naturelle de Savoie (in French).

Mugaruka Bibentyo, T., S. Kulimushi Matabaro, W. Muhindo Sahani, and O. Dewitte. 2017. Anatomy of Nyakavogo landslide (Bukavu, DR Congo): Interplay between natural and anthropogenic factors (Glissement de terrain de Nyakavogo (Bukavu, $R D$ Congo): interaction entre facteurs naturels et anthropiques). Geo-Eco-Trop 41(2): 249-262 (in French).

Nobile, A., A. Dille, E. Monsieurs, J. Basimike Tchangaboba, T. Mugaruka Bibentyo, N. D’Oreye, F. Kervyn, and O. Dewitte. 2018. Multi temporal DInSAR to characterise landslide ground deformations in a tropical urban environment: Focus on Bukavu (DR Congo). Remote Sensing 10(4): Article 626.

Nojavan, M., E. Salehi, and B. Omidvar. 2018. Conceptual change of disaster management models: A thematic analysis. Jàmbá: Journal of Disaster Risk Studies 10(1): Article 451.

Oliver-Smith, A. 1986. The martyred city: Death and rebirth in the Andes. Albuquerque: University of New-Mexico press.

Peiry, J.L., P.G. Salvador, and F. Nouguier. 1994. River-bed incision in the Northern Alps: A state of the art (L'incision des rivières dans les Alpes du Nord: état de la question). Revue de Géographie Alpine 69(1): 47-56.

Piegay, H. 1997. New principles relating to the management of braided streamways: Example of the mid-Giffre valley in HauteSavoie (Principes nouveaux en matière de gestion des marges de rivières en tresses). Revue de Géographie Alpine 85(2): 33-48 (in French).

Pigeon, P. 2002. Reflections on the geography of so-called natural hazards (Réflexions sur la géographie des risques dits naturels). H.D.R. thesis, Université de Nice-Sophia-Antipolis (in French).
Pigeon, P. 2005. Géographie critique des risques. Paris: Anthropos. Pigeon, P. 2014. Dike risk: Defending a systemic and geopolitical reconsideration of environmental risks (Risque digue: Une justification à la relecture systémique et géopolitique des risques environnementaux). L'espace Politique 24: Article 3.

Pigeon, P. 2016. Dike risk: Revealing the academic links between disaster risk reduction, sustainable development, climate change and migration. In Identifying emerging issues in disaster risk reduction, migration, climate change and sustainable development: Shaping debates and policies, ed. K. Sudmeier-Rieux, K. Fernández, I. Penna, I. Jaboyedoff, and J.C. Gaillard, 67-80. London: Springer.

Pigeon, P., and J. Rebotier. 2016. Disaster prevention policies. London: Elsevier.

Renaud, F.G., K. Sudmeier-Rieux, and M. Estrella. 2013. The role of ecosystems in disaster risk reduction. Bonn: United Nations University Press.

Reyntjens, F. 2009. The great African war-Congo and regional geopolitics, 1996-2006. Cambridge: Cambridge University Press.

Rockström, J., M. Falkenmark, C. Folke, M. Lannerstad, J. Barron, and E. Enfors. 2014. Water resilience for human prosperity. Cambridge: Cambridge University Press.

Shi, P., C. Jaeger, and Q. Ye. 2013. Integrated risk governance: Science plan and case studies of large-scale disasters. London: Springer.

Shi, P., and R. Kasperson. 2014. World atlas of natural disaster risk. New York: Springer.

Sidle, R.C., and T.A. Bogaard. 2016. Dynamic earth system and ecological controls of rainfall-initiated landslides. Earth-Science Reviews 159: 275-291.

Turner, B.L., R.E. Kasperson, P.A. Matson, J.J. McCarthy, R.W. Corell, L. Christensen, N. Eckley, J.X. Kasperson, et al. 2003. A framework for vulnerability analysis in sustainability science. Proceedings of the National Academy of Sciences of the United States of America 100(14): 8074-8079.

UNISDR (United Nations International Strategy for Disaster Reduction). 2009. UNISDR terminology on disaster risk reduction. Geneva, Switzerland: UNISDR. https://www.unisdr.org/files/ 7817_UNISDRTerminologyEnglish.pdf.

UNISDR (United Nations International Strategy for Disaster Reduction). 2015. Making development sustainable: The future of disaster risk management. Global Assessment Report on Disaster Risk Reduction (GAR), Geneva, Switzerland: United Nations Office for Disaster Risk Reduction (UNISDR). https://sustaina bledevelopment.un.org/index.php?page $=$ view $\&$ type $=400 \& n r=$ 2046\&menu=1515. Accessed 14 Dec 2019.

UNISDR (United Nations International Strategy for Disaster Reduction). 2017. UNISDR terminology on disaster risk reduction. Geneva, Switzerland: UNISDR. https://www.unisdr.org/files/ 52828_nationaldisasterriskassessmentpart1.pdf. Accessed 19 Feb 2020.

Wisner, B., P. Blaikie, T. Cannon, and I. Davis. 2004. At risk: Natural hazards, people's vulnerability and disasters, 2nd ed. London: Routledge.

Wisner, B., J.C. Gaillard, and I. Kelman. 2012. Framing disaster: The Routledge handbook of hazard and disaster risk reduction. London: Routledge. 